OPEC governments, how credible is an OPEC promise to increase production if a shortfall has political ramifications? And if an unintended interruption occurs, how likely is it that OPEC will be able to restrain the high-absorber members from charging what the market will bear? If, as is probable, they cannot, consumers will have paid higher-than-market prices in normal times in return for broken promises.

Would the benefits exceed the costs? Basically, consumers would gain a formal framework for debating production (and price) decisions that are now entirely in OPEC hands. Bilateral diplomacy can have some of the same effect. How much is it worth paying for this framework?

These questions do not mean that conversations with producer states are not useful, or that restoration of an international oil regime is not a worthy long-term goal. Various bilateral and multilateral discussions are essential. But efforts to reconstruct a satisfactory regime are unlikely to be fruitful unless hard questions have been carefully thought through. The volume at hand provides raw material for such thinking, but poses few of those questions and gives disappointingly few of the answers.

Joseph S. Nye is Professor of Government and Public Policy at Harvard University.

\title{
The state of Arab science
}

\section{Ziauddin Sardar}

Science and Science Policy in the Arab World. By A. B. Zahlan. Pp.205. (Croom Helm: 1980.) £13.95.

THE past decade has seen scientific and technological activity in the Middle East really come alive. While much of this activity is little more than simple transfer of equipment, expertise and personnel, there are, nevertheless, a number of projects which aim to make a real contribution to science development in the area and provide it with an indigenous base; to this end a number of technological universities and specialized institutes have been established to meet some of the more demanding needs of manpower and research.

The scale of this transfer of technology and its associated problems are in many respects unique and unparalleled, and demand urgent and detailed scholarly attention. Thus one turns to Antoine Zahlan's book with the hope of seeing these developments charted, analysed and placed in an appropriate scientific, social and political context. Indeed, few would be better qualified for such a job.

With so much to relate and analyse, it is sad to report that Zahlan has missed an excellent opportunity. His book is not just weak in content and rather limp in its analysis; worse, it is a book apparently based almost entirely on publicity brochures and official handouts. Probably the best part is the introduction where Zahlan allows himself some critical consideration. However, from that point onwards, the book consists of straightforward description, potted history and dubious statistics.

The opening chapter presents a general view of the growth of scientific activity in the Arab World. Zahlan uses three basic sources for his information: UNESCO's List of Scientific Papers Published in the Middle East (1948-1955), the now defunct Arab Science Abstracts (1973-1975) and Who is Publishing in Science. I would not be able to say anything about Arab science on the basis of these sources. Further I do not believe, as Zahlan does, that "scientific productivity measured in terms of publications of academic institutions is highly correlated with their scientific standing as assessed by leading scientists; it is also related to other outputs such as inventions, patents and the technological performance of the economy'. These sorts of criteria for scientific productivity may be applicable to highly developed economies with sophisticated scientific infrastructures, but not to developing economies where scientists have more pressing concerns than

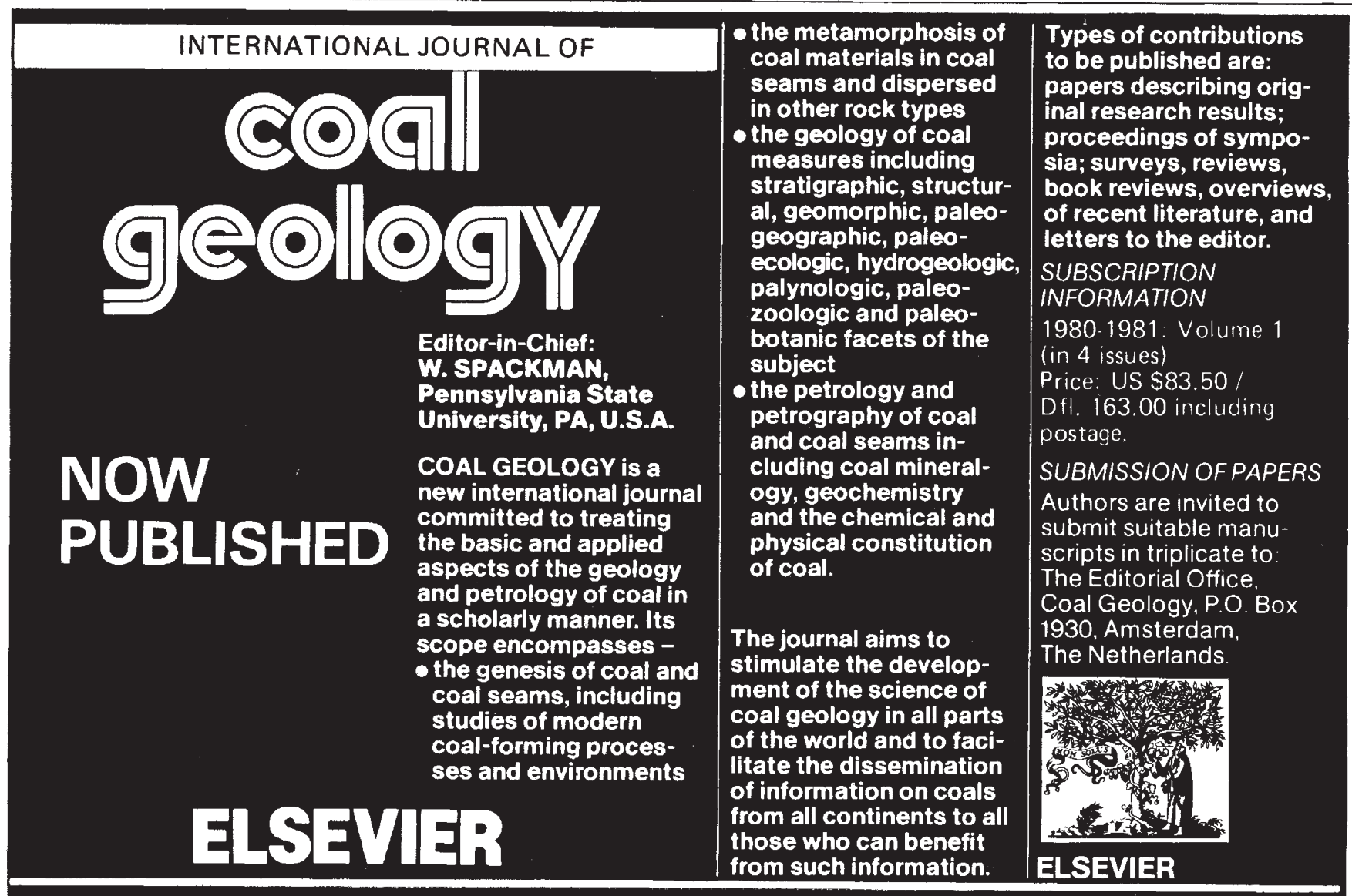

Send for your sample copy now. 
publication. Zahlan himself is aware of the shortcomings of his methodology. However, no one is really any wiser at the end of the exercise.

As Egypt has the most highly developed scientific infrastructure in the Middle East, Zahlan appropriately devotes a whole chapter to the country. It is very much a historical discussion that traces science development in Egypt from 1951. An attempt is made to chart the development of scientific activity by measuring the increases in BSc and $\mathrm{PhD}$ degree holders (what is an Egyptian $\mathrm{PhD}$ worth, in real scientific terms, anyway?). Most of the statistics are taken from government ministries and technical institutes and no attempt is made to indicate the level of reliability of the figures. After Egypt, scientific activities in "selected countries" are presented: five pages on Kuwait, just over two on Iraq, less than a page on Saudi Arabia - which has one of the most rapidly expanding scientific bases in the Middle East, with astronomical sums being spent on science and technological development - and a half-page on Syria. Is that all that is happening in these countries and in the Middle East as a whole? Is nothing going on in Sudan, Algeria, Tunisia and Jordan?

After a similarly patchy and brief treatment of scientific manpower, we reach the last three chapters on funding, international and regional cooperation, and science policy, where at least an attempt has been made to be more thorough. The chapter on funding does manage to bring out both the channels being developed to fund scientific research and development and the resources available to capital-rich and capital-poor Arab states. The chapter on international and regional cooperation amounts to little more than the minutes of meetings of the Conference of Ministers of Arab States Responsible for the Application of Science and Technology to Development, and relies heavily on national papers submitted by Arab states to the recently held UN Conference on Science and Technology for Development. It is certainly not scholarship, neither is it good journalism, but it works as an account of recent history. This is also true of the chapter on science policy; here the commentary suffers by uncritical reproduction of material from brochures and annual reports such as that of Cairo's National Research Centre.

So, what value can one place on Science and Science Policy in the Arab World? The book has little of value to say about science policy, and even less about science, in the Middle East. But the book works, to a certain extent, as a history of science in the Middle East in general, and Egypt in particular, during the 1950s and 1960s. It is surprising that Zahlan has nothing much to say about recent - post-1975 developments in science and technology. $\mathrm{He}$ seems to have overlooked the controversies about "Arabization" of science, planning and developing technical institutions and universities, scientific bureaucracies and the debate on Islamic science. Perhaps these omissions are deliberate, but some discussion of these issues would have saved him from the accusation that the book is remarkably boring. Perhaps Zahlan feels that he has

\section{Landau in retrospect}

\section{H.B.G. Casimir}

Landau: A Great Physicist and Teacher. By Anna Livanova. Pp. 217. (Pergamon: 1980.) £10, $\$ 22.50$.

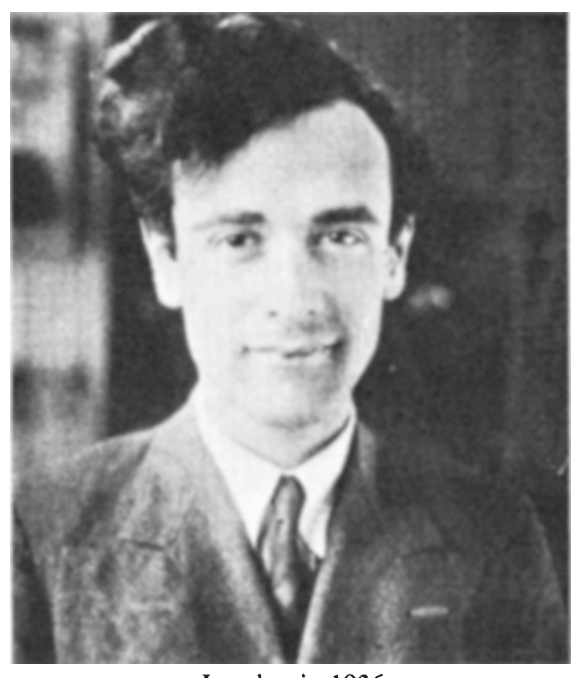

Landau in 1936

LEV Davidovich Landau (1908-1968) was a brilliant theoretical physicist, an outstanding teacher and a striking personality, with an influence spreading far beyond the circle of his students and coworkers; his merciless criticism may have antagonized some of its victims, but he was most helpful and encouraging to anyone he considered worth helping. These characteristics are clearly brought out in Anna Livanova's well-written book. Although it is neither an exhaustive biography nor a critical appraisal of the whole of Landau's contributions to physics, the author has succeeded admirably in re-creating the image of this great man and in explaining to a general reader his ways of working and teaching.

The book opens with a brief biography. Landau was born at Baku and entered the university there at the age of 14. In 1924 he moved to Leningrad, graduating in 1927. Livanova gives a short but lively description of his student days. He learnt a little from his professors, quite a bit from discussions with fellow students - but most just by himself.

In 1929 he set out on an extended visit to western Europe and England. He went to see Pauli at Zürich, collaborated there with Peierls and wrote his famous paper on said it all elsewhere in one of his many excellent publications. If this is so, then why write such an empty book?

Ziauddin Sardar is Middle East Science Consultant to New Scientist and author of Science, Technology and Development in the Muslim World.

diamagnetism (the description of which, by Livanova, leaves something to be desired). At Cambridge he met Kapitza, the beginning of a lifelong friendship, but of even greater influence on Landau were his contacts with Niels Bohr at Copenhagen. Livanova reports that Landau later regarded Bohr as his one and only teacher. That may seem surprising; I cannot think of two prominent physicists who differed more widely in their approach to teaching. Livanova calls attention to this difference, but in my opinion she does not sufficiently stress this point. I believe Bohr's influence was so important because his way of looking at physics was complementary to Landau's self-taught virtuosity. Landau had far more in common with Pauli in that they possessed comparable intellectual power and mathematical skills, and both could on occasion be redoubtable critics. Even so, there was a profound difference in their choice of subjects.

In 1932 Landau became head of the theoretical division of the Ukrainian Physicotechnical Institute at Kharkov. There he began teaching in earnest, collaborated with the experimentalists especially with Shubnikow who had set up a cryogenic laboratory - and published a number of important papers. He left Kharkov in 1937 for Moscow and there he remained as head of the theoretical division of Kapitza's Institute of Physical Problems until his death in 1968; he always refused to become head of an institute of his own.

After a serious motor car accident in 1962, Landau became practically an invalid. One can sympathize with Anna Livanova in not entering into details concerning these later years, but I find it regrettable that, although she hints at difficulties at Kharkov, she does not mention that Shubnikow was arrested and never heard of again, and that Landau spent about one year in prison in 1938 and 1939 and might have perished but for Kapitza's courageous intervention.

For me, the most fascinating chapter is that concerned with "The School of Landau'". This shows Landau at the height of his powers and gives a lively picture of his particular style and methods.

About half of the book is devoted to a description of Kapitza's work on the superfluidity of liquid helium and Landau's theoretical work in this field. The author preferred to consider one important and characteristic contribution of Landau's in detail instead of discussing superficially the whole of his work, and in 